\title{
As Agendas ODS no Plano Plurianual 2016-2019¹
}

Rodrigo Correa Ramiro²

\section{INTRODUÇÃO}

O ano de 2015 marcou o avanço de dois importantes processos que balizariam o debate sobre o desenvolvimento nacional nos anos subsequentes: a fase final de elaboração do Plano Plurianual (PPA) 2016-2019, no plano nacional, e a aprovação da Agenda 2030, no plano internacional.

Como forma de avaliar a convergência entre o planejamento de médio prazo do governo federal e o mais abrangente compromisso internacional assumido pelo país, realizou-se um esforço de alinhamento entre o PPA e os Objetivos de Desenvolvimento Sustentável (ODS). A partir do cruzamento das metas e iniciativas do PPA com as metas dos ODS, foram criadas as Agendas ODS, que organizavam os atributos do PPA que contribuíam para o alcance de cada objetivo e meta da Agenda 2030.

A construção das Agendas ODS foi inspirada na experiência da construção das agendas transversais, que representavam recortes temáticos dos atributos do PPA para explicitar agendas como igualdade racial e pessoa idosa, com o intuito de dialogar, principalmente, com os respectivos conselhos de políticas públicas no âmbito da participação social no PPA.

As Agendas ODS confirmaram o grau elevado de convergência entre PPA e ODS e foram parte da estratégia brasileira de internalização da Agenda 2030 em conjunto com os processos de adequação de metas à realidade nacional, construção dos indicadores e territorialização da agenda.

Este artigo tem como objetivo avaliar a experiência da elaboração das Agendas ODS, no âmbito dos esforços para a internalização da Agenda 2030 no país e do monitoramento e avaliação do PPA, e está organizado em três seçóes, além desta introdução. $\mathrm{O}$ histórico do conceito de desenvolvimento sustentável e sua representação na Agenda 2030 são objetos da próxima seção. Na terceira seção é apresentado o processo de construção das Agendas ODS no âmbito do PPA 2016-2019 e seus principais resultados. A seção 4, por fim, é composta pelos comentários conclusivos.

\section{A INSTITUCIONALIZAÇÃO DO CONCEITO DE DESENVOLVIMENTO SUSTENTÁVEL E A AGENDA 2030}

A noção de desenvolvimento sustentável consagrada no relatório da Comissão Mundial sobre Meio Ambiente e Desenvolvimento como “(...) o desenvolvimento que garante o atendimento das necessidades do presente sem comprometer a habilidade das geraçóes futuras de atender suas necessidades" (CMMD, 1988, p. 46) buscou compatibilizar o crescimento econômico com a preservação ambiental, após as disputas entre defensores do "crescimento zero" e desenvolvimentistas que caracterizaram a inserção da temática ambiental na agenda internacional desde a Conferência das Naçóes Unidas sobre o Meio Ambiente Humano, ocorrida em Estocolmo em 1972 (Sachs, 1993; Mueller, 2012).

1. DOI: http://dx.doi.org/10.38116/bapi28art5

2. Analista de planejamento e orçamento; e doutorando em relações internacionais na Universidade de Brasília (UnB). 
O conceito de desenvolvimento sustentável, gestado na academia e nos espaços políticos-diplomáticos globais, é baseado de uma forma vaga no tripé eficiência econômica-sustentabilidade ecológica-equidade e pode ser visto simultaneamente como veículo de um acordo político mínimo em torno dos termos em que se daria a institucionalização da temática ambiental em âmbito global e como ponto de partida da disputa política a ser travada nos limites traçados pelo próprio conceito (Nobre, 2002). Neste caso, destaca-se o papel das grandes conferências/acordos internacionais sobre desenvolvimento e meio ambiente ${ }^{3}$ na institucionalização do conceito.

A gênese da visão atual sobre desenvolvimento sustentável, a Agenda 2030, se deu a partir da experiência acumulada entre as conferências Rio-92 e Rio+20 e teve como uma de suas principais referências os Objetivos de Desenvolvimento do Milênio (ODMs), adotados internacionalmente pela Resolução no 55/2/2000 (ONU, 2000). Os oito ODMs eram compostos por 21 metas, envolvendo temas que vão desde a erradicação da extrema pobreza e da fome, passando pelo o combate ao HIV/Aids, chegando à proteção ambiental (Lago, 2006).

O grande mérito dos ODMs foi estabelecer metas claras e concisas, de fácil comunicação e passíveis de monitoramento, que nortearam a ação coordenada dos países entre 2000 e $2015 .^{4}$ Embora os avanços na adoção dos ODMs fossem notáveis, houve críticas principalmente pela forma top-down com que eles foram elaborados, com baixa participação dos países-membros e da sociedade civil, além de não considerar compromissos internacionais já assumidos e as diversidades regionais e locais no estabelecimento das metas (Araújo, 2019).

As resoluções da Rio+20 definiram os processos para a construção da agenda sucedânea dos ODMs. Para tanto, foi criado o Grupo de Trabalho Aberto sobre os Objetivos de Desenvolvimento Sustentável (GTA-ODS), que, entre 2012 e 2015, envolveu cerca de setenta países, inclusive o Brasil, e diversos atores da sociedade civil na elaboração de uma proposta que embasou os ODS. Em setembro de 2015, na Cúpula sobre o Desenvolvimento Sustentável da Organização das Nações Unidas (ONU), a nova agenda de desenvolvimento global foi adotada por unanimidade pelos 193 Estados-membros da ONU. Os ODS, compostos por dezessete objetivos e 169 metas, fazem parte de uma agenda recomendatória ${ }^{5}$ que traduziu o consenso possível entre os países sobre desenvolvimento sustentável. Eles entraram em vigor em 1ำ de janeiro de 2016, adotando uma perspectiva abrangente e universal, considerando explicitamente

as diferentes realidades nacionais, as capacidades e os níveis de desenvolvimento, respeitando as políticas e prioridades nacionais. São objetivos e metas universais que se aplicam ao mundo todo, tanto aos países desenvolvidos quanto aos em desenvolvimento. Eles são integrados e indivisíveis, e mesclam, de forma equilibrada, as três dimensóes do desenvolvimento sustentável (ONU, 2015, p. 3).

3. Para uma visão geral das grandes conferências ambientais, ver Nobre (2002) e Lago (2006).

4. Os ODMs foram adotados pelo governo brasileiro, que em alguns casos propôs metas mais ambiciosas do que as originais. Em grande medida, esta adoção foi motivada pelo fato de que os ODMs possuíam correspondência com as políticas brasileiras do período. Para uma avaliação da atuação brasileira, ver os relatórios voluntários coordenados pelo Ipea, como Ipea (2014), e Roma (2019).

5. A Agenda 2030 alinha-se aos acordos internacionais recentes, como os ODMs, acordos estes que, ao invés da formulação normativa tradicional em que o acordo internacional é incorporado à legislação nacional (rule making), propõem a adoção de mecanismo de estabelecimento de metas de caráter recomendatório (goal settings), cuja implementação depende de uma governança envolvendo diversos atores. Estas mudanças derivam de um cenário de crise do multilateralismo e das suas instituições e também respondem a um aumento da complexidade das relações e a um novo paradigma democrático (Araújo, 2019). 
No intuito de promover e implantar a Agenda 2030 no Brasil, foi instituída, por meio do Decreto nº 8.892/2016, a Comissão Nacional para os Objetivos de Desenvolvimento Sustentável (CNODS), com a finalidade de

internalizar, difundir e dar transparência ao processo de implementação da Agenda 2030 para o Desenvolvimento Sustentável da Organização das Nações Unidas, subscrita pela República Federativa do Brasil. (...) A Comissão Nacional para os Objetivos de Desenvolvimento Sustentável é instância colegiada paritária, de natureza consultiva, integrante da estrutura da Secretaria de Governo da Presidência da República, para a articulação, a mobilização e o diálogo com os entes federativos e a sociedade civil (Brasil, 2016c).

A CNODS era composta por dezesseis membros, com o assessoramento permanente do Ipea e do Instituto Brasileiro de Geografia e Estatística (IBGE), conforme expresso na figura 1, e sua missão era

criar mecanismos institucionais que estabeleçam as condiçóes adequadas à implementação dos ODS, incluindo estratégias para a territorialização, a definição de metas e indicadores, processos participativos, meios de implementação, acompanhamento e monitoramento da Agenda 2030 (CNODS, 2017, p. 9).

\section{FIGURA 1}

Composição da CNODS (2017-2019)

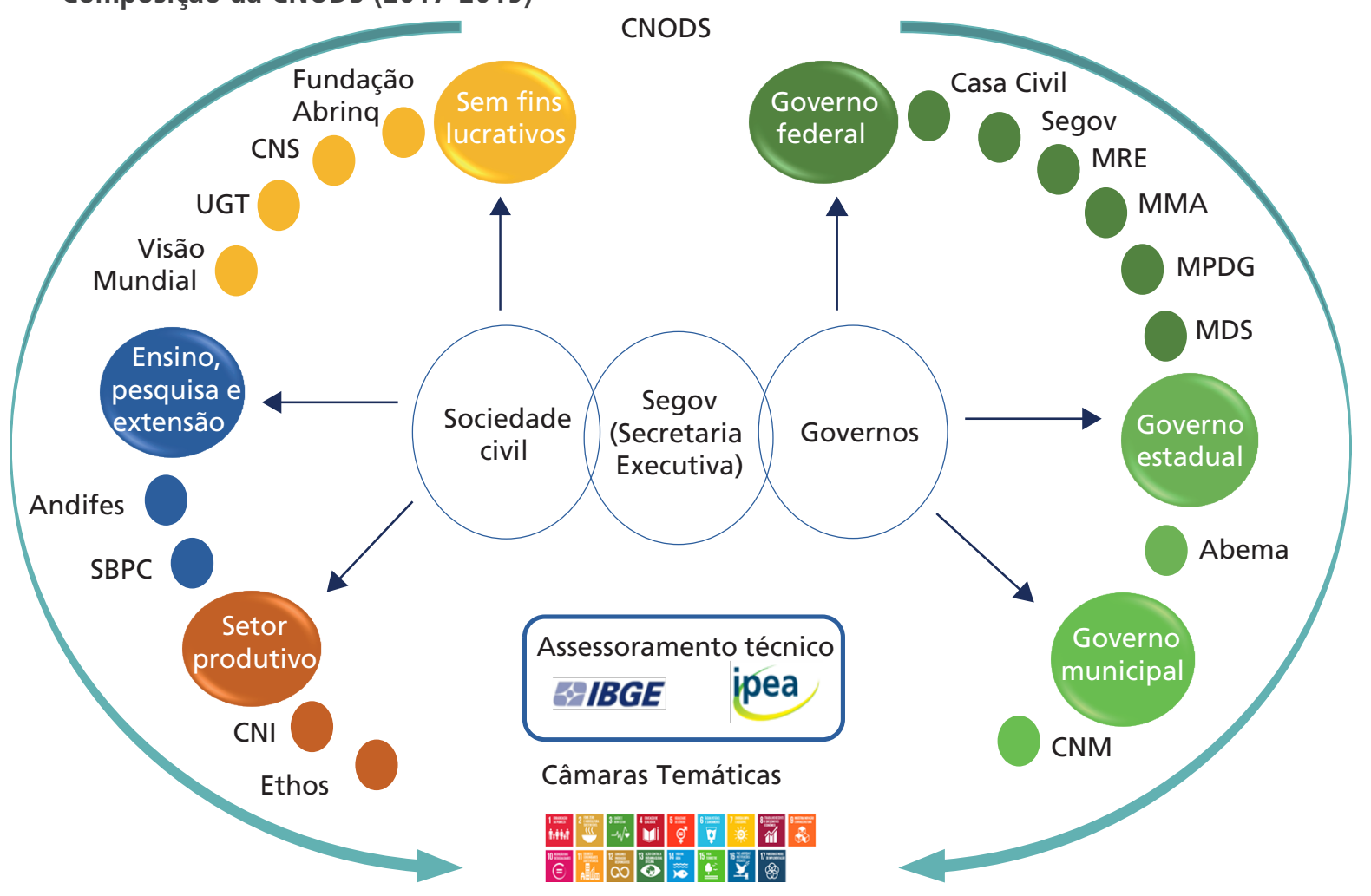

Fonte: CNODS (2017, p. 13).

Obs.: Fundação Abrinq - Associação Brasileira dos Fabricantes de Brinquedos; CNS - Conselho Nacional das Populações Extrativistas; UGT - União Geral dos Trabalhadores; Andifes - Associação Nacional dos Dirigentes das Instituições Federais de Ensino Superior; SBPC - Sociedade Brasileira para o Progresso da Ciência; CNI - Confederação Nacional da Indústria; Segov - Secretaria de Governo da Presidência da República; MRE - Ministério das Relações Exteriores; MMA - Ministério do Meio Ambiente; MPDG - Ministério do Planejamento, Desenvolvimento e Gestão; MDS - Ministério do Desenvolvimento Social; Abema - Associação Brasileira de Entidades Estaduais de Meio Ambiente; CNM Confederação Nacional de Municípios. 
Entre as principais açóes da CNODS, destacaram-se: i) a adequação das metas dos ODS à realidade nacional, conduzida pelo Ipea (Ipea, 2018); ii) a definição dos indicadores nacionais dos ODS, em processo liderado pelo IBGE; ${ }^{6}$ e iii) a criação das Agendas ODS no Sistema Integrado de Planejamento e Orçamento (SIOP), liderada pelo então MPDG. O processo de construção das Agendas ODS no SIOP é objeto da próxima seção.

As principais iniciativas da CNODS estavam em consonância com a proposta de internalização da Agenda 2030 nos instrumentos de planejamento nacional, ou com a transição para os ODS, ambas contidas na Resolução no 70/1 da ONU, que estabeleceu os ODS.

As metas são definidas como ideais e globais, com cada governo definindo suas próprias metas nacionais, guiados pelo nível global de ambição, mas levando em conta as circunstâncias nacionais. Cada governo também vai decidir como essas metas ideais e globais devem ser incorporadas aos processos, nas políticas e estratégias nacionais de planejamento (ONU, 2015, p. 13).

Nós encorajamos todos os Estados-membros a desenvolver, logo que possível, respostas nacionais ambiciosas para a aplicação global da presente agenda. Estas podem apoiar a transição para os ODS e construir sobre os instrumentos de planejamento existentes, tais como as estratégias de desenvolvimento nacional e de desenvolvimento sustentável, conforme o caso (ONU, 2015, p. 39).

Em que pese a consonância dessas iniciativas com a Agenda 2030, as açóes do governo brasileiro, de uma forma geral, e da CNODS, em particular, para implementação dos ODS foram desarticuladas e ocorreram de forma tardia. A intensa participação brasileira na construção da Agenda 2030 não se consolidou imediatamente em uma governança nacional para os ODS. A instabilidade política, que culminou no processo de impeachment em 2016, retardou a decisão de instituir a CNODS, sendo que sua concretização se deu por forte pressão da sociedade civil organizada. ${ }^{7}$

Sobre os resultados das açóes, Araújo (2019, p. 138) destaca que a CNODS, "apesar de seus tímidos acertos, não esteve à altura dessa trajetória [de participação brasileira na Agenda 2030]”. Entre os fatores que contribuíram para este quadro, destacam-se: a falta de comprometimento de lideranças nacionais, dos três Poderes, com os ODS; e a ascensão do novo governo em 2019 com uma posição avessa ao multilateralismo e identificada com a hegemonia conservadora em relação à agenda ambiental.

As ações de cunho mais técnico coordenadas pelo IBGE sobre os indicadores tiveram continuidade no tempo, tendo sido iniciadas anteriormente às da CNODS, e fazem parte do escopo de trabalho da instituição, mas outras ações da CNODS foram descontinuadas ou não foram sequer iniciadas. A adequação das metas dos ODS conduzida pelo Ipea e concluída no segundo semestre de 2018, na véspera da eleição presidencial, não foi alvo do devido processo de consulta pública ou encaminhamento oficial da CNODS para aprovação presidencial, por falta de decisão política para tal, tendo se resumido a um valioso exercício realizado por servidores públicos federais. Já o processo de interiorização/territorialização da agenda ocorreu de forma espontânea por iniciativa de alguns estados e municípios, sem a participação ou orientação da CNODS. Por fim, a CNODS foi extinta,

6. Os resultados estão disponíveis em: <https://odsbrasil.gov.br/>.

7. Para mais detalhes sobre o processo de instituição da CNODS e a pressão da sociedade civil para a instituição de uma governança sobre os ODS no Brasil, ver Nilo (2016). Vale ressaltar que a sociedade civil, por meio do Grupo de Trabalho da Sociedade Civil para a Agenda 2030 do Desenvolvimento Sustentável, elabora anualmente um relatório de acompanhamento da Agenda 2030 no país. Os relatórios luz, como são conhecidos, estão disponíveis em: <https://gtagenda2030.org.br/>. 
junto com mais de uma centena de colegiados, pelo Decreto no 10.179, de 18 de dezembro de 2019 (Brasil, 2019a), reafirmando a posição do novo governo de abandono da Agenda 2030.

\section{AS AGENDAS ODS 8}

O processo de elaboração do PPA 2016-2019 se baseou, com aprimoramentos pontuais, na metodologia do PPA 2012-2015 e seguiu as principais diretrizes estratégicas adotadas pelo governo federal desde o PPA 2004-2007.

O PPA 2016-20199 foi estruturado em duas grandes dimensões: a estratégica e a tática/programática. A dimensão estratégica era subdividida em visão de futuro, eixos e diretrizes, enquanto a dimensão tática compreendia os programas temáticos. Estes eram recortes selecionados de políticas públicas que expressavam e orientavam a ação governamental. Cada programa era composto por: i) objetivos que expressavam as escolhas de políticas públicas para o alcance dos resultados almejados pela intervenção governamental e faziam o vínculo com as açôes orçamentárias e com os financiamentos extraorçamentários; ii) metas, quantitativas ou qualitativas, que mediam o alcance do objetivo; e iii) iniciativas que declaravam os meios e mecanismos de gestão que viabilizavam os objetivos e suas metas, explicitando a lógica da intervenção (Brasil, 2016a; 2016b).

Os ODS, por sua vez, estão estruturados em dezessete objetivos que expressam os principais desafios contemporâneos. Como demonstra a figura 2, as estruturas do PPA e dos ODS não possuem correspondência direta, apesar de utilizarem termos comuns como objetivos e metas.

FIGURA 2

Atributos dos ODS e do PPA 2016-2019

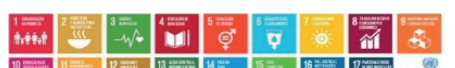

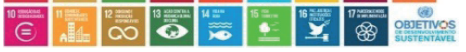

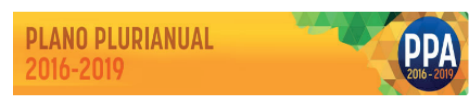

Objetivos ODS $=17$

Metas ODS $=169$

Indicadores ODS $=241$

Fonte: Brasil (2018a, p. 16).

\section{Programas PPA $=54$}

Objetivos PPA = 303

Metas PPA $=1.132$

Iniciativas PPA = 3.094

Os objetivos dos ODS são mais abrangentes do que os programas e os objetivos do PPA. Assim, a decisão metodológica foi por um cruzamento no nível de metas dos ODS e metas e iniciativas do PPA.

Esta decisão metodológica permitiu ter uma visão das ações do governo federal que contribuem para o alcance de cada meta ODS, sendo possível agregá-las por objetivo da Agenda 2030, da mesma forma é possível agregar as metas ODS por programa do PPA ou órgão federal. Assim, o alinhamento resultou na construçáo de uma base de dados contendo as metas e iniciativas do PPA 
que se relacionam com as metas ODS, de forma direta ou indireta, obtendo-se assim um panorama abrangente das relaçóes entre PPA e ODS que podem ser agregados ou desagregados conforme a necessidade da análise (Brasil, 2018a, p. 15).

Esse panorama abrangente, contudo, possuía limitaçóes metodológicas. Os conceitos de relação direta ou indireta entre os atributos do PPA e dos ODS não estavam bem definidos. Além disso, o cruzamento não seria suficiente para avaliar o grau de alcance das metas dos ODS a partir da execução do PPA, ou seja, se todos os atributos do PPA relacionados a determinada meta ODS fossem devidamente executados, qual seria a porcentagem de alcance desta meta? Esta deficiência era agravada pelo fato de que diversos atributos, tanto do PPA como dos ODS, eram qualitativos.

O processo de construção das Agendas ODS era iniciado pela Secretaria de Planejamento e Assuntos Econômicos (Seplan)/MPDG, que elaborava uma proposta inicial do cruzamento. Esta versão preliminar era encaminhada ao órgão responsável pela política para revisão e posteriormente era validada, em reunião envolvendo a Seplan/MPDG, a Secretaria Nacional de Articulação Social (SNAS)/Segov e os órgãos setoriais. ${ }^{10}$ Assim, os esforços de alinhamento implicaram um processo contínuo de aprimoramento e interação entre órgãos federais. Este trabalho de alinhamento envolveu a participação de cerca de 250 servidores de 29 instituiçóes federais e teve o mérito de integrar as diversas instituiçóes do Executivo federal em torno das discussóes sobre a Agenda 2030. ${ }^{11}$

O resultado do cruzamento confirmou a expectativa de elevada convergência entre os instrumentos. Verificou-se que $95 \%$ das metas dos ODS possuíam algum atributo do PPA relacionado à sua implementação. Todos os programas do PPA 2016-2019 apresentam atributos relativos a algum ODS e a divisão destes atributos agregada por dimensão é bem distribuída, como mostra a figura 3. Os resultados do trabalho permitiram obter uma visão geral das relaçóes entre as políticas públicas federais e os compromissos assumidos pelo país no âmbito da Agenda 2030.

10. Para testar a metodologia proposta foi realizado um piloto com o MMA em que se definiu a necessidade de uma sensibilização sobre a Agenda 2030, de uma forma geral, e sobre a proposta de alinhamento entre PPA e ODS, em particular, para os órgãos setoriais, além de promover momentos de troca de experiências entre os órgãos.

11. 0 processo de alinhamento, em particular os intercâmbios entre os órgãos, levou a algumas externalidades positivas, como "i) o compartilhamento de experiências e práticas entre os ministérios envolvidos nos trabalhos; ii) a criação de instâncias voltadas para o acompanhamento dos ODS dentro dos ministérios setoriais, como no Mapa [Ministério da Agricultura, Pecuária e Abastecimento], CGU [Controladoria-Geral da União] e MS [Ministério da Saúde]; e iii) a disseminação da Agenda 2030 no âmbito do serviço público federal" (Brasil, 2018a, p. 16). 
FIGURA 3

Alinhamento dos atributos dos ODS e do PPA 2016-2019 por dimensão

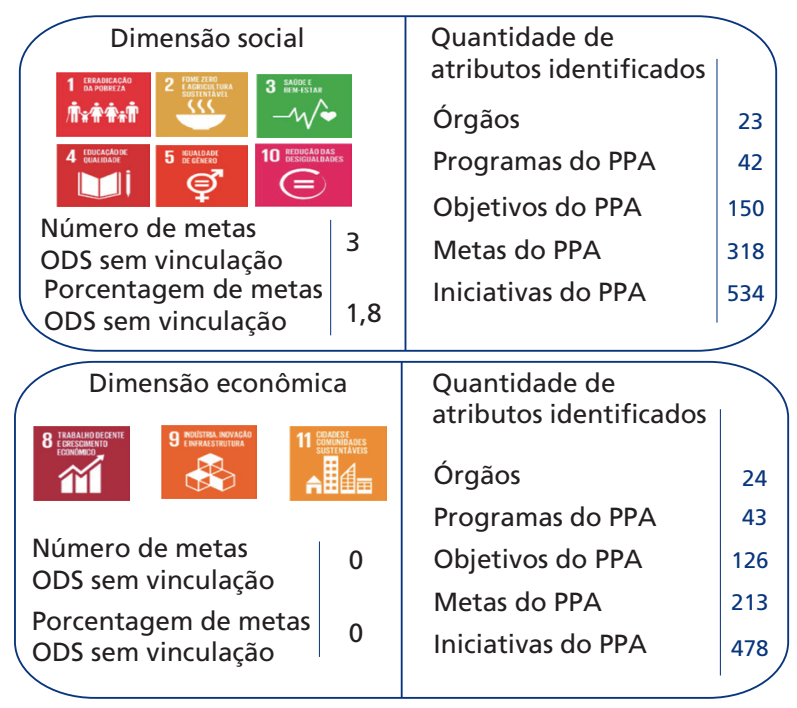

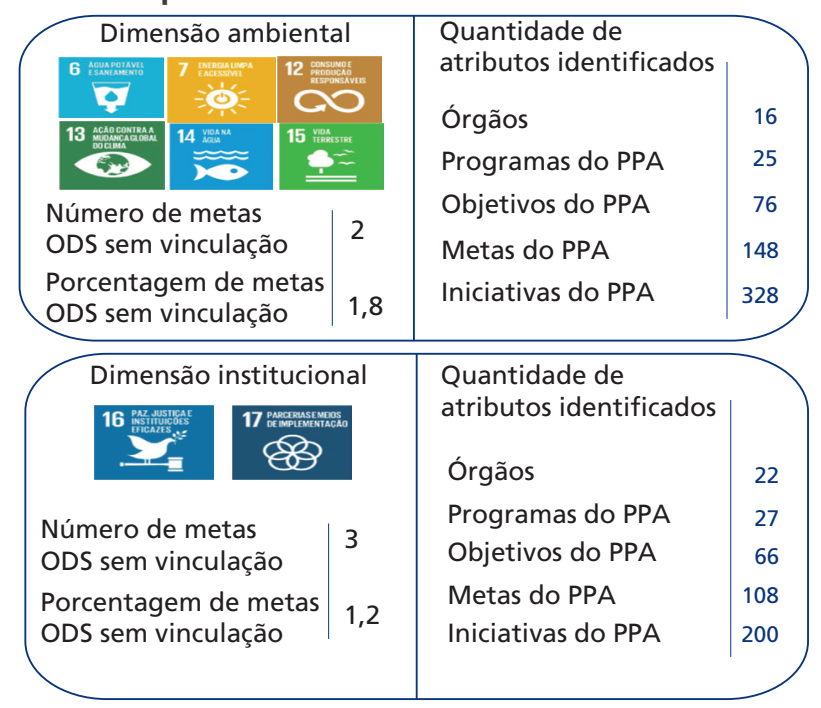

Fonte: Brasil (2018a, p. 18).

Uma vez alinhados os atributos do PPA e dos ODS, foi possível criar as Agendas ODS no SIOP, conforme previsto no plano de ação da CNODS de 2017-2019 (CNODS, 2017). É importante destacar que a criação das Agendas ODS foi baseada na experiência do MPDG com as agendas transversais fruto dos esforços de ampliar a participação social no PPA. ${ }^{12}$ As agendas do PPA são

recortes transversais de seus atributos onde são agregados os programas, objetivos, metas e iniciativas relacionados a um público (como povos indígenas, criança e adolescente, LGBT [lésbicas, gays, bissexuais, travestis, transexuais e transgêneros], entre outros) ou temática específica (como usos múltiplos da água, economia solidária). A lógica de construção das agendas no âmbito do PPA permite a agregação de açóes antes dispersas no plano em um lócus comum, permitindo entender como determinado tema transversal é tratado no plano como um todo (Brasil, 2018a, p. 20).

Assim como no caso das agendas transversais, o acompanhamento das Agendas ODS seria utilizado para prestar contas à sociedade e subsidiar as discussóes do Fórum Interconselhos. A ideia era promover facilidade de acesso e transparência das informaçóes. Para tanto, também foi desenvolvida a plataforma eletrônica PPA Cidadão, ${ }^{13}$ com todas as informaçóes sobre as agendas do PPA.

O processo de alinhamento dos atributos do PPA e dos ODS permitiu o acompanhamento das Agendas ODS em 2018, com base nos dados de 2017 (Brasil, 2018a). Esse acompanhamento foi consolidado num relatório de governo, em que foram destacados os principais avanços na execução do PPA 2016-2019 e sua relação com os ODS. Apesar da previsão anual, o relatório de 2018 foi o único publicado. Desta forma, não houve espaço para aprimoramento metodológico no processo de construção das Agendas ODS.

12. A participação social no PPA é analisada em estudo deste boletim intitulado A quem serve a participação? Experiência democrática do Fórum Interconselhos no Plano Plurianual 2016-2019, de Daniel Pitangueira de Avelino, Eduardo Gomor dos Santos e Felipe Portela Bezerra. As agendas estão disponíveis em: <https://bit.ly/3/L8cUj>.

13. Disponível em: <https://ppacidadao.planejamento.gov.br/sitioPPA/>. 
Além dos relatórios de acompanhamento, previstos no plano de ação da CNODS, a experiência derivada da construção das Agendas ODS deveria ter sido utilizada para subsidiar a elaboração do PPA 2020-2023. A proposta da Seplan/MPDG ${ }^{14}$ era de que o novo PPA definisse as metas intermediárias a serem alcançadas até 2023 - compatíveis com as metas nacionais adaptadas para 2030 - e as ações necessárias para alcançá-las. Esta proposta não foi acatada pela nova direção do MPDG, agora Ministério da Economia.

O PPA 2020-2023 apresentado pelo Executivo federal ao Congresso não fazia referência aos ODS e foi emendado para inclusão da seguinte diretriz geral: "persecução das metas dos Objetivos do Desenvolvimento Sustentável da Organização das Nações Unidas" ${ }^{15}$ Esta emenda parlamentar, claramente insuficiente para afirmar o compromisso do país com a Agenda 2030, e única menção aos ODS no PPA 2020-2023 foi alvo de veto presidencial. ${ }^{16}$ Assim, foi consolidada a posição do governo federal, apesar de signatário da Resolução no 70/1 da Assembleia Geral das Naçóes Unidas, de não dar continuidade às açôes federais relacionadas aos ODS.

\section{COMENTÁRIOS CONCLUSIVOS}

A institucionalização da temática ambiental e do conceito de desenvolvimento sustentável evoluiu e se consolidou desde a Conferência de Estocolmo, em 1972, até o estabelecimento da Agenda 2030, em 2015. Este processo se caracteriza como uma arena de disputa de interesses e construção de consensos envolvendo centenas de países, representantes de governos e da sociedade civil, e organismos internacionais.

A construção dos ODS, que contou com a participação concertada de milhares de atores desde 2012, incluindo governo e sociedade civil brasileira, considerou explicitamente a necessidade do estabelecimento de governanças locais, a adequação de metas e a inclusão dos ODS nos processos de planejamento nacionais. As Agendas ODS, foco deste artigo, eram o primeiro passo de um processo de internalização dos ODS no planejamento nacional que culminaria na elaboração do PPA 2020-2023, considerando explicitamente a implementação dos ODS. Este processo, apesar do mérito de inspirar um esforço concertado de órgãos federais sobre a Agenda 2030, se limitou à produção de um relatório de acompanhamento das Agendas ODS, sem influenciar a elaboração do novo PPA.

A atuação do Poder Executivo federal na Agenda 2030 foi marcada pela instituição da CNODS, quase dois anos após a adoção dos ODS, e por forte pressão da sociedade civil. As principais atividades desenvolvidas pela CNODS, como a adequação de metas à realidade nacional, a definição dos indicadores nacionais e a criação das Agendas ODS no SIOP, foram, em grande parte, descontinuadas em 2019. A extinção da CNODS marcou o afastamento do governo federal da Agenda 2030 sem a proposição de uma estratégia alternativa, o que é sintomático da dificuldade do país em construir um planejamento de longo prazo.

\footnotetext{
14. Na proposta de nova metodologia de elaboração do PPA era previsto que ele deve declarar o compromisso do governo federal com a implementação dos ODS para o período entre 2020-2023 e que a construção dos seus atributos deve considerar a implementação da Agenda 2030 no nível de metas ODS (direta ou indireta), segundo informações de apresentações realizadas pelo MPDG aos outros ministérios.

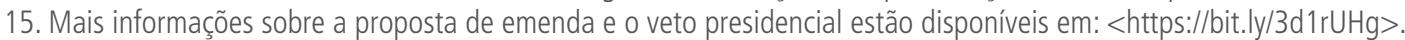

16. 0 veto foi justificado com o seguinte argumento: "o dispositivo, ao inserir como diretriz do PPA 2020-2023 a persecução das metas dos Objetivos do Desenvolvimento Sustentável da Organização das Nações Unidas, sem desconsiderar a importância diplomática e política dos Objetivos do Desenvolvimento Sustentável da Organização das Nações Unidas, acaba por dar-Ihe, mesmo contrário a sua natureza puramente recomendatória, um grau de cogência e obrigatoriedade jurídica, em detrimento do procedimento dualista de internalização de atos internacionais, o que viola a previsão do art. 49, inciso I, e art. 84, inciso VIII, da Constituição Federal" (Brasil, 2019b).
} 


\section{REFERÊNCIAS}

ARAÚJO, A. B. A. A Agenda 2030 para o desenvolvimento sustentável e o Brasil: uma análise da governança para implementação entre 2015 e 2019. 2019. Dissertação (Mestrado) - Instituto de Economia e Relaçóes Internacionais, Universidade Federal de Uberlândia, Uberlândia, 2019.

BRASIL. Lei no 13.249, de 13 de janeiro de 2016. Institui o Plano Plurianual da União para o período de 2016 a 2019. Diário Oficial da União, Brasília, 14 jan. 2016a. Disponível em: <http:// www.planalto.gov.br/ccivil_03/_ato2015-2018/2016/Lei/L13249.htm>.

. Decreto no 8.759, de 10 de maio de 2016. Regulamenta a Lei no 13.249, de 13 de janeiro de 2016, que institui o Plano Plurianual da União para o período de 2016 a 2019. Diário Oficial da Uniáo, Brasília, 11 maio 2016b. Disponível em: <http://www.planalto.gov.br/ccivil_03/_ato20152018/2016/decreto/D8759.htm>.

. Decreto no 8.892, de 27 de outubro de 2016. Cria a Comissão Nacional para os Objetivos de Desenvolvimento Sustentável. Diário Oficial da Uniáo, Brasília, 31 out. 2016c. Disponível em: <http://www.planalto.gov.br/ccivil_03/_ato2015-2018/2016/decreto/d8892.htm>.

. Ministério do Planejamento, Desenvolvimento e Gestão. Agendas ODS no SIOP: relatório anual de monitoramento - ano-base 2017. Brasília: Seplan/MP, 2018a. Disponível em: <http:// bibliotecadigital.seplan.planejamento.gov.br/handle/123456789/1075?show=full>.

. Ministério do Planejamento, Desenvolvimento e Gestão. PPA 2016-2019: relatório anual de avaliação - ano-base 2017. Brasília: MP, 2018b. Disponível em: <https://bit.ly/3c75Wne>.

. Decreto no 10.179 , de 18 de dezembro de 2019. Declara a revogação, para os fins do disposto no art. 16 da Lei Complementar no 95, de 26 de fevereiro de 1998, de decretos normativos. Diário Oficial da Uniáo, Brasília, 19 dez. 2019a. Disponível em: <http://www.planalto.gov.br/ ccivil_03/_Ato2019-2022/2019/Decreto/D10179.htm\#art1>.

. Mensagem no 743, de 27 de dezembro de 2019. Diário Oficial da União, Brasília, 30 dez. 2019b. Disponível em: <http://www.planalto.gov.br/ccivil_03/_ato2019-2022/2019/Msg/ VEP/VEP-743.htm>.

CMMD - COMISSÃO MUNDIAL SOBRE MEIO AMBIENTE E DESENVOLVIMENTO. Nosso futuro comum. Rio de Janeiro: Editora FGV, 1988.

CNODS - COMISSÃO NACIONAL PARA OS OBJETIVOS DE DESENVOLVIMENTO SUSTENTÁVEL. Plano de açáo 2017-2019. Brasília: CNODS, 2017. Disponível em: <http:// www4.planalto.gov.br/ods/publicacoes/plano-de-acao-da-cnods-2017-2019>.

IPEA - INSTITUTO DE PESQUISA ECONÔMICA APLICADA. Objetivos de Desenvolvimento do Milênio: relatório nacional de acompanhamento. Brasília: Ipea; SPI/MP, 2014.

. ODS: metas nacionais dos Objetivos de Desenvolvimento Sustentável. Brasília: Ipea, 2018.

LAGO, A. A. C. do. Estocolmo, Rio, Joanesburgo: o Brasil e as três conferências ambientais das Naçóes Unidas. Brasília: Funag; IRBr, 2006.

MUELLER, C. C. Os economistas e as relaçóes entre o sistema econômico e o meio ambiente. Brasília: Editora UnB, 2012. 
NILO, A. A participação da sociedade civil na Agenda 2030 da ONU e a política externa brasileira: um exercício de democracia nas relações internacionais. 2016. Monografia (Especialização) Faculdade Damas, Recife, 2016.

NOBRE, M. Desenvolvimento sustentável: origens e significado atual. In: NOBRE, M.; AMAZONAS, M. de C. (Org.). Desenvolvimento sustentável: a institucionalização de um conceito. Brasília: Ibama, 2002.

ONU - ORGANIZAÇÃO DAS NAÇÕES UNIDAS. Declaraçáo do milênio. Nova Iorque: ONU, 2000.

. Transformando nosso mundo: a Agenda 2030 para o desenvolvimento sustentável. Nova Iorque: ONU, 2015.

ROMA, J. C. Os Objetivos de Desenvolvimento do Milênio e sua transição para os Objetivos de Desenvolvimento Sustentável. Ciência e Cultura, v. 71, n. 1, p. 33-39, jan./mar. 2019.

SACHS, I. Estratégias para o século XXI. In: BURSZTYN, M. (Org.). Para pensar o desenvolvimento sustentável. Brasília: Editora UnB, 1993. 